\title{
Do Pós-MODERno aO Pós-ANTIGo
}

\author{
MARCUS VINICIUS DE FREITAS \\ Departamento de Letras Vernáculas \\ Faculdade de Letras - UFMG
}

\begin{abstract}
REsUM0
Dor paralelismo com o conceito de pós-moderno seria possível pensar o conceito 1 de pós-antigo? Este último termo é usado de maneira rápida por Mikhail Bakhtin em sua análise da obra de François Rabelais, ao reportar-se à Antigüidade tardia. Para além do recorte histórico incluso no termo, pode-se perceber uma tentativa de uso conceitual que revela uma atitude crítica em relação ao conhecimento da Antigüidade. 0 presente texto propõe-se justamente avançar, a partir das categorizações propostas pela pós-modernidade, o proto-conceito bakhtiniano, especialmente no que concerne às questōes da originalidade, do lugar do saber teórico e dos usos da tradição.

Palavras-chave: Pós-moderno; Pós-antigo; Gêneros literários; Luciano.
\end{abstract}

El pasado es arcilla que el presente labra a su antojo. Interminablemente.

Jorge Luis Borges

\section{Do Pós-moderno ao Pós-ANTigo}

\footnotetext{
Abra crítica de Mikhail Bakhtin pode ser vista como um esforço incessante para definir $A$ e expor o que, em suas próprias palavras, seria o cânon grotesco. Os esforços sobre as $\mathcal{L}$ Lobras de Luciano, Rabelais ou Dostoiévski constituiriam, vistos dessa perspectiva, estudos de caso a partir dos quais o grotesco se mostraria. Oposto ao cânon clássico, de largo conhecimento e reconhecimento na cultura ocidental, o cânon grotesco demandaria um trabalho de reconstrução crítica capaz de informar obras deixadas de lado pela história da crítica, exatamente por terem sido submetidas a critérios alheios a elas, critérios clássicos:
} 
No domínio artístico, conbecemos o cânon clássico, que nos serve de guia até um certo ponto na atualidade; o mesmo não ocorre com o cânon grotesco que já há muito tempo deixou de ser compreensivel ou do qual temos apenas uma compreensão distorcida. A tarefa dos historiadores e teóricos da literatura e da arte consiste em recompor esse cânon, em restabelecer seu sentido autêntico. (Bakhtin, 1993, p. 26)

Bakhtin coloca-se na perspectiva de quem pensa a história da arte como história dos gêneros. Deve-se sobretudo compreender que, aqui, história significa mudança, ou seja, gêneros não são formas fixas, ao contrário, são estruturas em mutação. 0 pensamento bakhtiniano, sempre coerentemente dialógico, propõe uma visão agonística dos discursos. Não por acaso, Bakhtin tem especial predileção pelos momentos de "crise" do clássico (a palavra deve vir entre aspas exatamente porque aceitar os momentos de irrupção do grotesco como crise do clássico seria não enxergar o topocentrismo conceitual aí presente). Dentre esses momentos, o final da antigïidade possui especial relevo: "Nos fins da Antigüidade, o tipo de imagem grotesca atravessa uma fase de eclosão e renovação, e abarca quase todas as esferas da arte e da literatura. (Bakhtin, 1993, p. 28)

Esse momento é designado pelo autor como pós-antigo (Bakhtin, 1993, p. 28). 0 termo possui, no contexto do raciocínio de Bakhtin, ao mesmo tempo uma função cronológica e qualitativa. Pós-antigo é o que segue cronologicamente ao antigo, sobretudo é o que coloca em jogo esse antigo, que repensa, refaz e recontextualiza o antigo. Pós-antigo é um modo de lidar com a tradição. Ainda que seja anacrônico, parece que estamos diante de uma problemática semelhante à que o pós-moderno coloca frente ao moderno. ${ }^{1}$ Tomemos como exemplo e ponto de partida o trabalho de Italo Moriconi (Moriconi, 1994), que estrutura seu raciocínio sobre o pós-moderno a partir da duplicidade conceitual criada pela justaposição do prefivo pós à palavra moderno. Se pensássemos o pós como situação diacrônica, pós-moderno reduzir-se-ia a neo-moderno, já que o moderno define-se intrinsecamente por essa busca da superação de si mesmo, por um movimento contínuo de revolução. Por outro lado, vistos de uma perspectiva sincrônica, moderno e pós-moderno são linhas de forças, princípios motores atuantes na história, para além de situações cronológicas rígidas:

Enquanto gesto de periodização bistórica, o pós-moderno repete o moderno; enquanto força de retrospecção e reelaboração, repõe o moderno em diferença.

É interessante observar que, no segundo caso, a duplicidade original se desdobra noutra duplicidade: mesmo bavendo ai diferença, há também repetição do moderno. (Moriconi, 1994, p. 22)

\footnotetext{
1 Devo ao Prof. Jacyntho lins Brandão a primeira sugestão da possibilidade de aproximar a problemática pós-moderna da reflexão crítica que a Antigüidade Tardia constrói sobre a Antigüidade Clássica, especialmente através da obra de Luciano de Samósata.
} 
Entre os pólos da diferença e da repetição, a afirmação de Moriconi explicita uma das mais importantes articulações propostas pelo pós-moderno, a partir da qual cabe pensar 0 pós-antigo: a superação da querela sobre a originalidade. A ansiedade do original não mais influencia os autores pós-modernos, e não se trata de descartar simplesmente a noção de original, mas de compreendê-la como uma das formas de repetir o já dito. Na repetição em diferença, paradoxo funcional, constitui-se o pós-moderno.

Essa lição é fundamental no movimento de repensar o pós-antigo. Se no pós-moderno, através da consciência da repetição, supera-se o mito da originalidade, no pós-antigo, através da consciência da originalidade supera-se o mito da repetição, em um raciocínio ao mesmo tempo simétrico e inverso. De fato, a primeira e constante afirmação da crítica é a de que não se poderia falar em originalidade, quando se trata da Antiguidade tardia (caracterizada no movimento da segunda sofística, que já para os antigos não constitui uma néa sofística e sim uma deutéra, a qual, sendo uma segunda e não uma nova, de alguma forma repete a antiga sofística). ${ }^{2}$ Se para muitos críticos seria improcedente falar sobre originalidade na Antiguiidade tardia, dada a amplitude da teoria e da prática da mimese, cabe lembrar que tal raciocínio deriva de uma compreensão estática da mimese, que a reduz a simples imitação, quando se trata fundamentalmente de uma prática de reelaboração, uma forma da póiesis. ${ }^{3}$ Por esta última via, se compreendemos que a originalidade absoluta é uma miragem, exatamente por isso podemos recolocá-la em circulação ao falarmos da Antiguiidade tardia, como bem coloca Jacyntho Lins Brandão:

Originalidade absoluta, entendida como o absolutamente novo, não existiria não só na Antigïidade, mas em qualquer outro período da longa bistória da literatura européia. Esta constitui um conjunto que torna inteligivel sua própria denominação só porque se manifesta como uma rede em que os objetos - os textos - estão em constante relação. $\hat{E}$ o sentido da bistória que regula essa relação, o que faz com que o novo esteja sempre colocado em face do que o antecedeu, processo de onde decorre seu sentido e o sentido novo que o antecedente assume a cada etapa de sua bistória. (Brandão, 1992, p. 106)

0 raciocínio de Brandão, tão explicitamente pós-moderno na sua concepção da história, constitui, quando aplicado à Antigüidade tardia, a noção de pós-antigo, ainda que aquele autor não use o conceito bakhtiniano. 0 rendimento do conceito de pós-antigo está no fato de que, a partir das reflexões pós-modernas, ele nos ajuda a nos desvencilharmos do elogio estéril dos clássicos, considerados como fontes, e da depreciação igualmente estéril da história

${ }^{2}$ Sobre a Segunda Sofística, conferir Cassin (1990). 0 pensamento da autora, que produz importantes ecos na reflexão pós-moderna sobre a relação entre discurso e verdade, procura compreender a segunda sofística no horizonte de uma logólogia, e não mais da filosofia, ou seja, ao critério da verdade sobrepõe-se o critério do discurso.

3 Sobre o conceito de mimese como não-imitação, conferir Lima (1980); e também Brandão (1992). Sobre a relação entre mimese e póiesis, cf. Iñigo (1961). 
literária, considerada como imitação. Pós-antigüidade constitui uma atitude crítica em relação à Antigüidade, posicionamento de repetição e diferença, que tanto se localiza no pósantigo historicamente considerado (a Antiguiidade Tardia), quanto no pós-antigo de qualquer época, força atuante na história.

Em sentido inverso, o pós-antigo, enquanto afinidade eletiva do pós-moderno, enquanto precursor construído, traz ao próprio pós-moderno uma consciência histórica, uma linha de tradição, e o vacina contra a doença infantil da invenção da roda. 0 pós-moderno ganha, assim, história, e pode-se pensar diacronicamente.

Para além da questão da originalidade, outro ponto de contato entre pós-moderno e pós-antigo configura-se no lugar ocupado pela teoria. Criticado em sua possibilidade de produzir conhecimento, o saber disciplinar viu-se, em nosso tempo, confrontado com outras formas de saber advindas dos planos vividos dos conteúdos históricos. As disciplinas universitárias, confrontadas com o mundo extra-muros, caminharam no sentido de diluir fronteiras, como aponta Frederic Jameson: "Hoje, se pratica mais e mais uma espécie de escrita simplesmente denominada 'teoria' que, ao mesmo tempo, é todas e nenhuma dessas matérias (...)". (Jameson, 1985, p. 17)

0 saber pós-filosófico da teoria constrói-se do intercâmbio entre disciplina e experiência, entre saber formal e práticas vitais, entre ação e contemplação. Daí o espaço agonístico ser o campo do pós-moderno. Tal dramatização do saber constitui-se também como valor fundamental no pós-antigo. Quando no diálogo de Luciano (Luciano, 1981, p. 381-382), o galo Pitágoras produz seu discurso cínico para o sapateiro Micilo, o que vemos é a produção de uma Filosofia prática, uma pós-filosofia que historiciza o saber filosófico através do riso; que faz a filosofia descer da pretensão à verdade e aterrisar no plano dos discursos e da temporalidade:

Micilo - E em que bomem ou mulber te converteste depois de ser Aspásia?

Galo - No cínico Crates.

Micilo - Pelos Dioscuros! Que diferença! De cortesã em filósofo!

Galo - Depois fui rei, posteriormente pobre, um pouco depois Sátrapa, depois cavalo, rã e outras incontáveis formas - seria longo enumerá-las todas - Vltimamente tenho sido galo repetidas vezes, pois me agrada este tipo de existência...

Se a voz sagrada de Pitágoras revela-se na boca de um gało cínico, já não há mais lugar para verdades filosóficas. Luciano, pós-antigo, manipula em sua teoria todo o saber da tradição, sem qualquer falso respeito, ao contrário, a partir da repetição em diferença, a partir do ato de colocar em tensão todos os discursos, seja a filosofia, a história ou a literatura.

No modo de lidar com a tradição, sobretudo, está o lugar de contato entre pós-antigo e pós-moderno. Micilo, o sapateiro, foi acordado de um sonho pelo canto do galo, que imediatamente começa a falar. 0 sapateiro indaga a si mesmo se não será aquilo também um sonho, 
um galo que fala e, sobretudo, que revela ser o filósofo Pitágoras reencarnado. A presença de um sonhador e seu sonho, que problematizam os limites da realidade, e cujo sonho/galo fala sobre a tradição, são uma imagem da afirmação de Ricardo Piglia: "La tradición tiene la estructura de un sueño: restos perdidos que reaparecen, máscaras inciertas que encerran rostros queridos". (Piglia, 1991, p. 60)

A relação da pós-modernidade com a tradição, relação esta que pode ser projetada na pós-antigüidade, constitui-se como um sonho de imagens alheias, uma manipulação da memória coletiva, um discurso com palavras estranhas em uma língua que é de todos porque já não é de ninguém. A obra de Ricardo Piglia, um escritor ciente das questões colocadas pela pós-modernidade, está povoada de imagens dessa natureza, onde a cultura contemporânea aparece metaforizada na recordação da memória alheia. Um exemplo seria a personagem Lazlo Malamiid, húngaro, especialista no Martín Fierro. Laslo só conhece do espanhol esse seu poema fundador (no caso argentino), e com ele tenta expressar-se.

Sempre achei que esse bomem que tentava se expressar numa língua da qual só conbecia o seu poema maior era uma metáfora perfeita da Máquina de Macedônio. Contar com palavras perdidas a bistória de todos, narrar numa lingua estrangeira. (Pligia, 1993, p. 24)

A máquina enlouquecida de Macedônio Fernandez, imagem da tradição fragmentada, da tradução impossível, aproxima-se do galo que cacareja a tradição. Uma diferença importante talvez seja o fato de que há na imagem de Piglia um traço de nostalgia que o ácido humor do diálogo luciânico não apresenta. Talvez o pós-moderno seja mais antigo do que o pós-antigo na sua nostalgia de um discurso impossível, na aceitação do passado como espólio.

Em outro texto de Luciano, $O$ deserdado, o tema da tradição é investigado de maneira muito peculiar, que o aproxima da noção de manipulação dos saberes herdados, que vimos apontando como lugar de diálogo entre pós-moderno e pós-antigo. Um pai deserda seu filho que, expulso, exilado, consegue estudar medicina. Quando seu pai enlouquece (lembremonos da Máquina de Macedônio) e é dado como caso perdido, o filho consegue curá-lo, sendo novamente aceito na familia. Entrementes, a madrasta do jovem também enlouquece. Como o médico diz que não pode curá-la, seu pai quer novamente deserdá-lo. 0 texto constitui-se na defesa do rapaz, carregada de ironia sobre o discurso do pai (a tradição).

A crítica tem classificado esse tipo de texto como apenas um exercício retórico, no qual o autor, escolhendo um "caso fictício", como diria Botella (Luciano, 1981, p. 224), exercita dispositivos discursivos. Devo discordar do comentador pois a escolha do assunto nunca é gratuita em um autor de ficção.

Antes de mais nada, cabe lembrar que o jovem torna-se médico, profissão que, por excelência, apresenta-se na obra luciânica como modelo do saber. Bakhtin, buscando no pós- 
antigo as referências dos textos de François Rabelais, aponta que a imagem do médico-filósofo é aquela que, sobre todas as outras, informa o pensamento do autor francês. A relação entre o sábio e a sabedoria, entre o saber da tradição e o saber da experiência hodierna são buscados por Rabelais na medicina hipocrática: "(...) transportar a sabedoria para a Medicina e a Medicina para a sabedoria (...) pois, na realidade, não bá diferença entre a sabedoria e a Medicina (...)". (Hipócrates apud Bakhtin, 1993, p. 315)

0 mesmo fundamento hipocrático aparece na obra de Luciano, em que o médico, nos vários diálogos em que sua figura é central, apresenta-se sempre como o sábio ao mesmo tempo integrado à tradição e dela distanciando-se, a partir de um ponto de vista crítico, especialmente quando a tradição constitui-se em discurso autoritário.

Desta forma, além de médico-filósofo (colocado em perspectiva crítica), o jovem é também "estrangeiro", dado que seu saber foi constituído como deserdado, longe da casa paterna. A própria personagem explica sua des-herança e sua deserção por ser ele mesmo "intratável e desobediente" (Luciano, 1981, p. 226); por envergonhar seu pai e ser indigno da família. No estatuto irônico do texto, o que se revela da fala do jovem é o fato de que sua posição em relação à tradição não é a da continuidade, como também não é a da ruptura, já que ele volta para curar o pai. A loucura paterna é exatamente o desejo de continuidade. Quando o filho cura o pai louco, o que ele cura é a tradição impositiva, e por isto mesmo impostora. Como seu saber, capaz de curar a tradição, foi adquirido enquanto estrangeiro, fora da própria herança, saber este que se volta para a mesma herança, não há mais como ser deserdado. Não há mais como deserdar quem já não está mais submetido às leis da herança, assim como não há tradição que possa impor-se sobre uma prática que já se tenha libertado das imposições da origem, da originalidade, tenha-se libertado da fidelidade da cópia ou da traição da paródia (também fiel, ainda que por oposição), prática que se constitui pela repetição em diferença.

Pensar as relações entre pós-moderno e pós-antigo parece-me importante em um duplo sentido. Recuperando a função conceitual do termo bakhtiniano, liberta-se o estudo da tradição da busca da matriz e o estudo da modernidade da crítica às fontes, por um lado; por outro, ao fundarmos precursores para a reflexão pós-moderna, evitamos a falácia de pensá-la como moda e, sobretudo, como última moda. Não há fim da história, porque não se pensa mais em começo. Há apenas jogo, embate, história.

FREITAS, M. V. From post-modern to post-ancient. Classica, São Paulo, v. 9/10, n. 9/10, p. 255-261, 1996/1997. 


\begin{abstract}
Could we parallel the concept of post-modern with the notion of a post-ancient? the Madder is used en passant by Mikhail Bakhtin in his analysis of François Rabelais's work when referring to the late Ancient Times. Besides the historical slant inherent to the term, there is an attempt to build a concept in its own right, which reveals a critical view of Ancient Times. From the perspective of the categorization built upon post-modernity, this work is an attempt to advance this bakhtinian proto-concept with regard to three specific issues: originality; the place of theoretical knowledge; and the use of tradition.

Key-words: Post-modern; Post-ancient; Literary genres; Lucian of Samosate.
\end{abstract}

\title{
Referências bibliográficas
}

BAKHTIN, Mikhail. A cultura popular na Idade Média e no Renascimento. Trad. Yara Frateschi. 2. ed., Brasilia/São Paulo: EdUnB/Hucited, 1993.

BAKHTIN, Mikhail. Problemas da poética de Dostoiéuski. Trad. Paulo Bezerra. São Paulo: Forense 'Universitária, 1980.

BRANDÃO, Jacyntho Lins. A poética do bipocentauro - identidade e diferença na obra de Luciano de Samósata. São: Paulo: Curso de Pós-Graduação em Letras da FFLCH/USP, 1992 (tese de doutorado).

BRANDÃO, Jacyntho Lins. "Doentes, doença, médicos e medicina em Luciano de Samósata". In: Cadernos de História e Filosofia da Ciência. Campinas: Série 2, II(2): 145-164, jul./dez. 1990.

CASSIN, Barbara. Ensaios sofísticos. São Paulo: Siciliano, 1990.

IÑIGO, Emílio Lledó. El concepto póiesis en la filosofia griega. Madrid: Consejo Superior de Investigaciones Científicas, 1961.

JAMESON, Frederic. "Pós-modernidade e sociedade de consumo". In: Novos Estudos CEBRAP. São Paulo: CEBRAP, 12, 1985.

LIMA, Luiz Costa. Mimesis e modernidade. São Paulo: Graal, 1980.

LUCIANO. Obras. Trad. y notas Andrés Espinosa Alarcón y Juan Zaragoza Botella. Madrid: Gredos, 1981. 3v.

MORICONI, Italo. A provocação pós-moderna. Rio de Janeiro: Diadorim, 1994.

PIGLIA, Ricardo. A cidade ausente. Trad. Sérgio Molina. São Paulo: Iluminuras, 1993.

PIGLIA, Ricardo. "Memória y tradición”. In: Anais do $2^{\circ}$ Congresso ABRALIC. Belo Horizonte: FALE/ UFMG, 1991. p. 60-66. 